\title{
Values at stake: autonomy, responsibility, and trustworthiness in relation to genetic testing and personalized nutrition advice
}

\author{
Karin Nordström • Niklas Juth • Sofia Kjellström • \\ Franck L. B. Meijboom • Ulf Görman · \\ on behalf of the Food4Me project
}

Received: 9 November 2012/ Accepted: 19 February 2013/Published online: 16 March 2013

(C) Springer-Verlag Berlin Heidelberg 2013

\begin{abstract}
Personalized nutrition has the potential to enhance individual health control. It could be seen as a means to strengthen people's autonomy as they learn more about their personal health risks, and receive dietary advice accordingly. We examine in what sense personalized nutrition strengthens or weakens individual autonomy. The impact of personalized nutrition on autonomy is analyzed in relation to responsibility and trustworthiness. On a societal level, individualization of health promotion may be accompanied by the attribution of extended individual responsibility for one's health. This constitutes a dilemma of individualization, caused by a conflict between the right
\end{abstract}

This study was conducted on behalf of the Food4Me project.

Food4Me is the acronym of the EU FP7 project: "Personalised nutrition: an integrated analysis of opportunities and challenges" (Contract no. KBBE.2010.2.3-02, Project no. 265494). The parties involved in the project are listed on the project's web site http://www.food4me.org/. Project coordination was carried out at University College Dublin, Ireland, Institute of Food and Health; Project Coordinator: Professor Michael J. Gibney, Project Manager: Dr. Marianne Walsh. For overall correspondence regarding the Food4Me project: Professor Michael J Gibney, UCD Institute of Food and Health, University College Dublin, Dublin, Ireland, Tel: +353 (1) 716 2824, e-mail: mike.gibney@ucd.i.e.

K. Nordström $(\bowtie) \cdot$ U. Görman

School of Education and Communication, Jönköping University, Jönköping, Sweden e-mail: karin.nordstrom@hlk.hj.se

\section{N. Juth}

Stockholm Centre of Healthcare Ethics,

Karolinska Institute, Stockholm, Sweden

\section{S. Kjellström}

Institute of Gerontology, School of Health Sciences,

Jönköping University, Jönköping, Sweden to individual freedom and societal interests. The extent to which personalized nutrition strengthens autonomy is consequently influenced by how responsibility for health is allocated to individuals. Ethically adequate allocation of responsibility should focus on prospective responsibility and be differentiated with regard to individual differences concerning the capacity of adults to take responsibility. The impact of personalized nutrition on autonomy also depends on its methodological design. Owing to the complexity of information received, personalized nutrition through genetic testing (PNTGT) is open to misinterpretation and may not facilitate informed choices and autonomy. As new technologies, personalized nutrition and PNTGT are subject to issues of trust. To strengthen autonomy, trust should be approached in terms of trustworthiness. Trustworthiness implies that an organization that develops or introduces personalized nutrition can show that it is competent to deal with both the technical and moral dimensions at stake and that its decisions are motivated by the interests and expectations of the truster.

Keywords Personalized nutrition - Ethics - Autonomy · Responsibility · Trustworthiness

\author{
F. L. B. Meijboom \\ Department of Philosophy, Ethics Institute, \\ Utrecht University, Utrecht, The Netherlands \\ U. Görman \\ Ethics Unit, Centre for Theology and Religious Studies, \\ Lund University, Lund, Sweden
}




\section{Introduction}

Personalized nutrition aims at providing more precise information about health effects of food intake than population-based dietary advice. Personalized nutrition may be seen as a tool to strengthen individual autonomy, as people learn more about their personal health risks, and by means of personalized dietary advice are provided with means to influence their health. Consumer studies indicate positive consumer attitudes and a perception of personalized nutrition as a potentially promising tool for improved health promotion. This is specifically associated with an expectation of individual empowerment with regard to one's health control (Stewart-Knox et al. 2009). The promotion of individual autonomy is thus a central feature of personalized nutrition. However, the actual impact on autonomy may vary. The aim of the article is to examine in what sense personalized nutrition strengthens or weakens individual autonomy. Autonomy is addressed as an ethical value at stake in relation to personalized nutrition. The term ethical value in this context designates values that are relevant for how we ought to act toward each other. The impact of personalized nutrition and, specifically, personalized nutrition through genetic testing (PNTGT) on autonomy is examined in relation to responsibility, trust, and trustworthiness. Two main issues, which influence the impact of personalized nutrition on autonomy, are identified and discussed. One issue concerns the understanding and regulatory allocation of responsibility for health; the other issue concerns the methods and procedures of personalized nutrition offerings.

\section{Autonomy as a value}

Generally characterized, to be autonomous is to govern oneself, and to live autonomously is to live in accordance with one's basic desires or values. Accordingly, autonomy is a matter of degree: a person can more or less lead the life they have chosen, more or less choose how to live, and their desires can be more or less their own. One can discern three components from this general characterization: will, decision, and action. How autonomous a person is in various parts of his or her life is determined by all these components, and they can all vary in degree. First, the proattitude with which one acts can be more or less authentic, that is, self-determined or truly the person's own. Second, one can be more or less decision competent, that is, more or less capable of successfully performing the task of deliberation. Third, one can be more or less efficient, that is, capable through action to realize that what one has decided upon (Juth 2005).

This general characterization of the nature of autonomy says nothing in itself about how autonomy matters morally.
Traditionally, in biomedical ethics, autonomy has primarily been considered as giving rise to restrictions for how we are allowed to treat each other: if an individual is adult and competent enough to make decisions, other people should not prevent that individual from making decisions and acting upon them-at least if that individual does not violate the rights of others (Locke 1689) or inflict damage on someone else (Mill 1859). According to this line of reasoning, we thus have a duty (at least of a prima facie kind) not to restrict the autonomy of others. In biomedical ethics, this line of reasoning has been taken as grounds for not being manipulated or coerced to accept a medical treatment. However, if we conceive of autonomy as a value, things become different. The question then is not primarily if we respect or do not respect someone's autonomous decisions. Rather, the question becomes how what we do can decrease or increase individual autonomy.

\section{Autonomy and responsibility within the dilemma of individualization}

Someone's autonomy is affected by the kind of social and relational context in which they live (Nordström 2009). Within personalized nutrition, autonomy is related to personal freedom with regard to diet and health. Respecting autonomy means to ensure that people are given access to sufficient relevant information, may choose freely which tests to undergo, may dispose of the test results, and are free to decide which dietarian advice to follow and what food to consume. Personalized nutrition may be seen as a means to strengthen autonomy as people learn more about their personal health risks by means of personalized dietary advice provided with tools to influence their health. However, increased knowledge about health risks and enhanced individual control over health are accompanied by increased social expectations and a higher attribution of responsibility for one's health. In this sense, "responsibility for health is a social value" (Kjellström 2005, p. 202). Thus, as a prerequisite for responsibility and autonomy, individualized health knowledge is ethically ambivalent.

The conditions of individual autonomy and responsibility with regard to health are embedded in a tension between societal and individual interests. The health of the individual is in the interest of society as a whole. This is illustrated by the fact that increasing attention has recently been given by governments to diet-related diseases and obesity (Smed 2012). Several countries have discussed interventions to stimulate healthy food consumption by means of fiscal measures (Tiffin and Arnoult 2011; Sacks et al. 2011). An example is the introduction of a fat tax in Denmark (Smed 2012). Interventions by governments such as the fat tax illustrate a tension between the individual's 
right to eat what one likes to eat and a societal interest to encourage healthier nutritional habits. In industrialized countries, morbidity and mortality have gradually shifted from spontaneous infections to chronic diseases (Marckmann 2010). The latter are caused by genetic disposition, external risk factors, and "health relevant behaviors" (Marckmann 2010). This has caused an increasing focus on health-promoting behavior (Görman 2006). The debate on progressively stricter policies for smoking, culminating in the proposal put forward in Iceland in 2011 for cigarettes to be available on prescription only, illustrates this. Nicholas Lezard, a journalist for The Guardian, pinpoints an inevitable, but problematic aspect of policies related to smoking bans: "A habit which is bad for me appears equivalent with what is bad of me." 1 While the awareness of something being bad for me allows for individual freedom, the notion of something being bad of me allocates social liabilities to the individual.

Thanks to information on individual presuppositions as well as knowledge of the possibilities of being influenced by them, personalized nutrition has the potential for making the individual more autonomous than is the case with general health and dietary advice. Yet individualization of health risks and health-promoting behavior may also facilitate the attribution of greater personal responsibility for one's health. For instance, this may be the case in stricter policies governing health insurance. Sanctions, such as restricted insurance rights in case of obesity, exemplify this. In Denmark, increasing numbers of cases are reported, where public health insurances require patients to loose weight for renewed rights for payments. ${ }^{2}$ This intensifies the conflict between individual and societal interests. Autonomy as the right of the individual to act according to his or her authentic preferences is challenged by society's interest in influencing individuals toward healthier lifestyles. Thus, owing to enhanced potential individual health control, there is also a risk of a negative impact on individual autonomy by such individualized health programs as personalized nutrition. In a scenario, where societies face increasing problems to finance healthcare costs, personalized nutrition may contribute to an ambivalent understanding of individual right to autonomy and responsibility for health. On the one hand, personalized nutrition provides tools for enhanced personal health control and improves the individual's possibility for health control. On the other hand, authorities and health insurances have an interest in inaugurating incentives for what is consequently considered as responsible nutritional

\footnotetext{
${ }^{1}$ http://www.guardian.co.uk/commentisfree/2011/jul/04/iceland-cigarettestub-out, accessed November 11, 2011.

2 http://www.dr.dk/Nyheder/Indland/2013/01/09/111913.htm?rss=true, accessed January 16, 2013.
}

habits or introduce sanctions for unhealthy nutritional habits. The presuppositions for individual autonomy are thus both improved and restricted. This constitutes the dilemma of individualization. An examination of how personalized nutrition affects autonomy renders significance to the way we understand and ascribe responsibility. With regard to autonomy, it is therefore important to reflect upon the ways we allocate responsibility for health to individuals as a consequence of their new knowledge and possibilities to influence their health. As is argued in the following sections, ethically adequate allocation of responsibility for health presupposes a differentiation between prospective and retrospective responsibility as well as an awareness of individual differences with regard to the capacity to take responsibility.

\section{Autonomy facilitated by prospective responsibility}

Autonomy and responsibility are closely interrelated. On the one hand, autonomy is a prerequisite of responsibility. On the other hand, responsibility, as a notion of liability, might constitute a threat to individual autonomy since personal freedom becomes constrained by the social norms attached to ideas of "correct" and "incorrect" behavior. With regard to personalized nutrition, it is necessary to consider the ethical implications of knowledge about one's health status and information about dietary means. Whether personalized nutrition strengthens or weakens autonomy depends on how it affects our understanding of individual responsibility for health. Here, a distinction between retrospective and prospective responsibility is vital. Retrospective responsibility charges somebody with liability or accountability; prospective responsibility is about a person's obligations toward somebody or for something. For both retrospective and prospective responsibility, autonomy or self-determination is a necessary prerequisite (Marckmann 2010). A basic principle for policy makers intending to promote an individual's autonomous role (and thus prospective responsibility) in health care and preventive medicine should be to focus on strengthening an individual's prospective responsibility, instead of attribution of retrospective individual responsibility (Marckmann 2010). Furthermore, socio-demographic conditions should be considered, since they affect the interest for autonomous decision making in health care-related issues. A higher desire for autonomy in healthcare decisions has been found among younger people, people with higher education, and people living alone (Cullati et al. 2011). Also, with regard to involvement in medical decision making, younger, higher educated patients and women have been found to prefer a more active role (Say et al. 2006). If there is an aim to enhance autonomy by means of personalized nutrition, 
socio-demographic aspects should thus be taken into account.

This view suggests that autonomy is strengthened if policies for preventive medicine succeed in retaining a focus on prospective responsibility. If the focus is shifted to encompass retrospective responsibility, individual autonomy is weakened. This is due to a related reduction in personal freedom since individuals are obliged to behave in accordance with public or individual health recommendations. As a preventive program, personalized nutrition may be described as including this ambivalent function with regard to autonomy and responsibility. Personalized nutrition may be seen as a tool for empowerment of individuals, strengthening their autonomy by providing the knowledge necessary for prospective responsibility. But individual autonomy is only strengthened if prospective responsibility is carefully distinguished from retrospective responsibility by policy makers. Personalized nutrition facilitates or strengthens autonomy, if people are encouraged to make informed choices and take prospective responsibility. But there is a risk of stigmatization of behavior that is regarded as conflicting with responsible conduct within solidarity systems. If this is accompanied by policies that result in increased retrospective responsibility, personalized nutrition potentially contributes to weaker individual autonomy.

\section{Individual responsibility for health: value and ability}

Personalized nutrition is based on a normative assumption of individual responsibility for health (Komduur et al. 2009; Bouwman et al. 2005). Health and dietary advice have a long history, but it was not until the 1970s that such advice was framed in terms of individual responsibility for health. Messages of individual responsibility for lifestyle and health have permeated medical, healthcare, and political discourse (Kjellström and Ross 2011) but often without reference to conditions and the implications of individual responsibility.

Positive adult development theories and empirical studies indicate that people continue to develop a range of complex capacities beyond adolescence (Loevinger and Blasi 1976). Health studies have often neglected the developmental nature of understanding responsibility. Adult development theories suggest the developmental and sequential nature of responsibility for health issues and discuss ethical implications in the field of personalized nutrition. Responsibility should be assigned to individuals in relation to their ability to take responsibility or having the prerequisites for being able to take responsibility.

Based on research from two fields of psychology, there is an empirical basis for a developmental sequence in reasoning about responsibility in general. Research on the attribution of responsibility for negative events (e.g. illness) indicates a specific pattern of assigning responsibility-from mere association to acknowledgment of the importance of knowledge and intentions of the agent (Fishbein and Ajzen 1973; Mantler et al. 2003). Adult development studies indicate three ways in which responsibility has a developmental nature. First, individual responsibility arises spontaneously at a certain level (Kajanne and Pirttila-Backman 1999 ENREF 29). Second, people have different abilities to comprehend and take responsibility owing to different interpretations of themselves, others, and the world in general (Loevinger and Blasi 1976). Third, the term "responsibility" means different things to different people depending on their stage of development (Dawson and Gabrielian 2003). Research into the question of taking responsibility for one's health has shown that developing such responsibility as an adult is associated with greater competence and changed behavior. Development of responsibility has, for example, been studied in relation to higher levels of physical self-care (Gast 1983), ways of thinking about food additives (Kajanne 2003; Kajanne and Pirttila-Backman 1999), autonomy (Loevinger and Blasi 1976), and understanding about responsibility for health (Kjellström 2005; Kjellström and Ross 2011).

Individual health behavior is created in a complex web of social, genetic, relational, individual, and biological influences. Social values, structures, and individual resources either facilitate or constrain how people actively take responsibility in the form of making healthy lifestyle choices and proactive decisions about health care and their future. Different adults reason in qualitatively different ways about responsibility and have different abilities to take responsibility. There seems to be a gap between people's capacities and the demands of society. A comprehension of adult development and the complexity of responsibility issues therefore seem vital for further development and application of personalized nutrition. Research into and the application of tailored dietary advice should be individually differentiated, not just with regard to genetic and phenotypic information, but also with regard to individual differences in the ability to relate to responsibility for one's own health.

Furthermore, from the point of view of autonomy, it is relevant that people may react to nutritional advice in ways that are incompatible with the presumptions in nutritional (and medical) advice. According to such presumptions, people will adjust their behavior as a result of the information in a way that is conducive to their future health (see Komduur et al. 2009). We need to know more about how disclosure of information can affect behavior in ways that are conducive to health and autonomy before stating that 
personalized nutrition will actually promote these values. For instance, one cannot preclude from the outset that some individuals will adopt a fatalistic attitude when learning, for example, that they have a higher genetic propensity for getting ill from eating much sugar: "if I'm going to get ill of health anyway due to my genes, I might as well try to have as much fun meanwhile and give into my sweet tooth." We will provide more examples of how these values may be compromised in the following section.

\section{Autonomy and personalized nutrition through genetic testing}

The impact of personalized nutrition on autonomy depends also on which method is applied. Personal dietary advice can be based on phenotype analysis, lifestyle analysis, and genetic testing. PNTGT has so far caused most debate with respect to ethical issues. There is disagreement over the question of whether the scientific knowledge basis is currently sufficient for PNTGT (Görman et al. 2013). This has implications for the ethical quest for autonomy. Owing to uncertainty and complexity with respect to the information obtained in PNGNT, we suggest that such analysis be focused on the matter of trust and trustworthiness. The ethically relevant difference between population-based nutritional advice and personalized nutrition is the fact that the latter is based on personal health data (of phenotype, lifestyle or genetic kind). Personalized nutritional advice is thus given in exchange with personal data. The interaction of the consumer with the company or institution offering a personalized nutrition service therefore involves aspects of trust and trustworthiness.

In the same way as personalized nutrition in general, PNTGT has the potential to promote autonomy. Since most of us need to have some degree of health in order to execute our plans and live the way we wish and PNTGT provides tools to promote health, in an indirect way, PNTGT also promotes autonomy. To be put into effect, plans in general require a certain capacity, and good health can maintain our capacity to do the necessary things to execute our plans. But a number of potential autonomyrelated drawbacks may also be identified with PNTGT.

One problem regards the difficulty in interpreting the information. As already noted, genetic information is often risk information. Nutritional advice on the basis of genetic tests is also very likely to be of a probabilistic kind since genes and nutrition interact in complex ways in increasing or decreasing the risk of disease. However, even if the risk estimations are adequate, there is the danger of misinterpreting them. First, it can be difficult to relate the risk figures based on genetics and statistical population studies to one's own situation. Second, several studies show that people often try to simplify numerical measures to rough estimations, interpreting risks as "50-50" when they are not and translating recurrence rates into "binary views"either it will or will not happen (Shiloh 1996, p. 88). Third, there are many often-cited examples of people's attitude toward risk being affected by presenting risks differently. One example that is especially common in relation to genetic and other medical information is to present relative rather than absolute risk figures (Juth and Munthe 2011). Suppose, for example, someone is told that he or she has a $35 \%$ higher risk of getting diabetes type 2 compared with the average population. This sounds high, but in terms of the average person's lifetime risk being, for instance, $2 \%$, a $35 \%$ higher risk of getting diabetes type 2 suddenly seems less serious, since their lifetime risk is still below $3 \%$ (it becomes $2.7 \%$ to be precise).

In terms of autonomy, the risk of misinterpreting such information is problematic. Someone may either underestimate the risk and follow a potentially dangerous diet or, more likely, he or she may overestimate it. This results not only in unnecessary anxiety, but also in restricting people's lifestyle without valid reasons. For example, someone may restrict himself to a certain diet that does not contain the foods he likes most, although the foods he denies himself would have negligible health effects.

\section{Trust and trustworthiness}

Since the individual receives personal information on health risks and dietary advice, autonomy may be strengthened. However, owing to the complexity of information given to the individual through PNTGT or personalized nutrition in general, informed choice becomes difficult and autonomy may also be weakened. To give helpful individual health advice presupposes that relevant and sufficient knowledge is made accessible. But owing to the complexity of information with regard to personalized nutrition (and many other medical techniques), each individual can be informed only to a certain degree. Therefore, information requires a certain amount of trust in suppliers of personalized nutrition. Linked to the question of autonomy as a value at stake is therefore the question of how personalized nutrition affects public trust in personalized nutrition and food products. Personalized nutrition is often developed as a way to give control to individuals to deal with health risks. At the same time, both health information and the food sector become more complex. As a consequence, an individual cannot but rely on many others. As a consumer, one is no longer able to assess personally all the risks and benefits of any particular product. Consequently, we are all necessarily part of complex webs of trust relationships, linking the person who 
trusts (the truster) to the person or institution whom he or she trusts (the trustee) (Meijboom 2007). Trust is essential for the food and health sectors because it is an attitude that is relevant if one is confronted with uncertainty or lack of personal control. The attitude of trust is a way of "managing uncertainty" (Becker 1996). In trusting, one acts "as if" certain possible states of affairs will not occur (Lewis and Weigert 1985). This is not an escape into some makebelieve world but is based on an assessment of the person or institution that one has to rely on. Personalized nutrition offerings are based on claims. These are related to information given on the health effect of specific nutrients for a certain individual, the method of how personal health data is processed into individually tailored nutritional advice, or recommended food supplements. The consumer who has no possibility to entirely verify the scientific basis of this procedure and associated claims has to decide, if the company or institution offering the service seems trustworthy or not. Utterly the trustworthiness of a company or institution offering personalized nutrition services depends on how personal health data are handled and whether the procedure applied to create value for the consumer is convincing.

Problems of trust may be dealt with by striving to reduce the need for trust, that is, reducing the uncertainty and/or giving the truster personal control. From this perspective, personalized nutrition can contribute to a reduction in the need to trust. On the one hand, improved knowledge of human genetics and further understanding of its relationship with certain ailments may help to translate uncertainties into risks that can be calculated by individuals. The occurrence of certain illnesses is no longer a black box but can be explained or even prevented with the help of knowledge about a person's genetic makeup. On the other hand, dietary advice may give certain levels of control to individuals. Personalized nutrition can provide tools to make autonomous decisions on how to deal with health risks. Consequently, it can reduce the need to trust.

Even though personalized nutrition can help individuals achieve better control over their health, it also presupposes trust. The obvious reason for trust is the high-tech character of tailor-made dietary advice. To use these services or products, which are at the interface between food and health, most individuals have to rely on many experts in the fields of human genetics, human health, and food. Only if one trusts the outcome of genetic tests, the interpretation by experts, and the adequacy of the proposed dietary advice is one in a position to better control one's own health. On top of this, personalized nutrition may extend the realm in which trust is required. In most situations, people who are offered personalized nutrition have not noticed any health risk. They did not consider their health status in terms of trust until the information on genetic risks alerted them.
Therefore, the range of situations in which one has to trust others will be extended (Meijboom 2007). Finally, trust may become complicated as a result of different patterns and routines in the food and health sectors. In each sector, one knows what one may expect in another. If personalized nutrition brings these sectors together, a reflection on mutual expectations is necessary to establish trustful relationships. Further research on regulative challenges of personalized nutrition products and services on the borderline between food and medicine is called for (Ahlgren et al. 2013).

\section{Personalized nutrition requires trustworthiness to strengthen autonomy}

The claim that trust is needed to make personalized nutrition operational can be easily understood as the problem of individual consumers or patients. It is necessary to rely on others in order to make full use of the promising characteristics of the various products. This, however, is too easy an approach for problems of trust. To make personalized nutrition strengthen autonomy, we should address questions of trust by starting with trustworthiness. There are three reasons for this step. First, there is a practical or conceptual argument: trust may not be enforced, because trust by definition requires a deliberate decision to trust by the truster. However, it is possible to show oneself as trustworthy. A company or institution offering personalized nutrition services can for instance show trustworthiness by documenting scientific competence of its employees or by means of transparency regarding affiliations and economic interests. A researcher can show trustworthiness for instance by disclosing conflicts of interests or by being a part of peer reviewing processes for the publication of research results. Second, there is the argument from implicit evaluation: if a trustee assesses the lack of trust as problematic, it includes an implicit claim about his trustworthiness. A company or institution offering personalized nutrition services can for instance investigate how enhanced transparency concerning its competence and interest can add to increased trustworthiness. Finally, even though a trusting relationship is by definition asymmetric and includes differences in knowledge and power, the truster should be treated as a person who is capable of autonomous agency. Consequently, the main question is not how the individual can be changed so that he will trust, but what conditions the trustee has to fulfill to be worthy of trust (Meijboom 2008).

In practice, this implies that those who are involved in the introduction of personalized nutrition should do more than emphasizing that the advice given and its procedures and products are safe. In contrast to someone who takes 
risks, a truster is not inviting, but coping with, complexity. Therefore, being trustworthy is different from allowing individuals to take risks. Second, trustworthiness is more than an emphasis on predictability. Predictability is often helpful, but is not enough for trust in new situations or in cases of conflicting expectations. Both are at stake since personalized nutrition is a novel practice and may result in conflicts, such as those between health and profit or autonomy and public health. In such situations, predictability is not sufficient for trustworthiness. This shows that trust requires clarity regarding mutual expectations. The common patterns we rely on in the food and health sectors are not only the result of routines, but also have a moral background. In both sectors, such values as safety, autonomy and justice play a central role. However, the interpretation of these values differs. Therefore, trustworthiness requires clarity regarding these expectations. This does not imply that an organization that wants to be seen as trustworthy needs to live up to all expectations. Given the plurality of views, that would be impossible. Trustworthiness implies that an organization that develops or introduces personalized nutrition is able to show that (a) it is competent to deal with both the technical and moral dimensions at stake and (b) its decisions are (also) motivated by the interests and expectations of the truster. This can lead to a balance between doing justice to the expectations of consumers and doing justice to the organization's core aims. This may not always result in trust, but it strengthens the truster's autonomy by enabling him to evaluate expectations, opportunities, and risks.

\section{Conclusions and challenges for further ethical analysis}

In this article, autonomy is addressed as a value at stake in relation to personalized nutrition. The impact of personalized nutrition and, specifically, PNTGT on autonomy is examined in relation to responsibility and trust or trustworthiness. The promotion of individual autonomy is a central feature of personalized nutrition; however, owing to various aspects of societal expectations and regulations, as well as the applied methods and procedures of personalized nutrition, the actual impact on autonomy may vary. By individualizing health, personalized nutrition is part of a dilemma of individualization. Reinforcing individual health control-and thus potentially individual autonomy-may provoke a clash between individual and societal interests with regard to responsibility for health. Retrospective and prospective responsibility present ethical challenges. One challenge consists of policies regarding insurance questions related to retrospective responsibility. It seems crucial that individualized health information and potentially improved individual control do not override principles of solidarity and justice in society. Concerning prospective responsibility, individual differences with regard to the ability to take responsibility demand further investigation. There is thus a need for individualization, not just as a matter of phenotype, lifestyle, or genetic variations, but also in relation to a psychological understanding of the capacity to take responsibility. This is also relevant because of the complex character of information obtained within PNTGT. The possibility of exercising autonomous decisions, specifically when dealing with complex information, is a matter of trust. Individual autonomy may be promoted if trust is regarded as a matter of trustworthiness; this needs to be studied in terms of the distribution of personalized nutrition. Standards of trustworthiness therefore also need to be the subject of further ethical analysis.

Conflict of interest None.

\section{References}

Ahlgren J, Nordgren A, Perrudin M, Ronteltap A, Savigny J, van Trijp H, Görman U, Nordström K (2013) Consumers on the internet-ethical and legal aspects of commercialization of personalized nutrition. Genes Nutr (this issue)

Becker LC (1996) Trust as noncognitive security about motives. Ethics 107:43-61

Bouwman LI, Hiddink GJ, Korthals M, Vam't Veer P, van Woerkum C (2005) Personalized nutrition communication through ICT application: how to overcome the gap between potential effectiveness and reality. Eur J Clin Nutr 59:108-116

Cullati S, Courvoisier DS, Charvet-Berard AI, Perneger TV (2011) Desire for autonomy in health care decisions: a general population survey. Patient Educ Couns 83(1):134-138

Dawson TL, Gabrielian S (2003) Developing conceptions of authority and contract across the lifespan: two perspectives. Dev Rev 23(2):162-218

Fishbein M, Ajzen I (1973) Attribution of responsibility: theoretical note. J Exp Soc Psychol 9(2):148-153

Gast HL (1983) The relationship between stages of ego development and developmental stages of health self care operations. Texas Woman's University, Texas

Görman U (2006) Ethical issues raised by personalized nutrition based on genetic information. Genes Nutr 1(1):13-22

Görman U, Mathers JC, Grimaldi KA, Ahlgren J, Nordström K (2013) Do we know enough? A scientific and ethical analysis of the basis for genetic based personalized nutrition. Genes Nutr (this issue)

Juth N (2005) Genetic information: values and rights. The morality of presymptomatic genetic testing. Acta Philosophica Gothoburgensia, Göteborg

Juth N, Munthe C (2011) The ethics of screening in health care and medicine-serving society or serving the patient?. Springer, Dordrecht

Kajanne A (2003) Structure and content: the relationship between reflective judgment and laypeople's viewpoints. J Adult Dev 10(3): 173-188

Kajanne A, Pirttila-Backman A-M (1999) Laypeople's viewpoints about the reasons for expert controversy regarding food additives. Pub Underst Sci 8(4):303-315. doi:10.1088/0963$6625 / 8 / 4 / 303$ 
Kjellström S (2005) Ansvar, hälsa och människa: en studie av idéer om individens ansvar för sin hälsa (Responsibility, health and the individual: a study of ideas on personal responsibility for health). Linköping University, Linköping

Kjellström S, Ross SN (2011) Older persons reasoning about responsibility for health: variations and predictions. Int J Aging Human Dev 72(2):99-124

Komduur RH, Korthals M, te Molder H (2009) The good life: living for health and a life without risks? On a prominent script of nutrigenomics. Br J Nutr 101:307-316

Lewis JD, Weigert A (1985) Trust as a social reality. Soc Forces 63(4):967-985

Locke J [1689] (1988) Two treatises of government. In: Laslett P (ed) Cambridge University Press, New York

Loevinger J, Blasi A (1976) Ego development: conceptions and theories, 1st edn. Jossey-Bass, San Francisco

Mantler J, Schellenberg EG, Page JS (2003) Attributions for serious Illness: are controllability, responsibility, and blame different constructs? Can J Behav Sci 35(2):142-152

Marckmann G (2010) Präventionsmaßnahmen im Spannungsfeld zwischen individueller Autonomie und allgemeinem Wohl (Prevention: the ethical tension between individual autonomy and population health). Ethik Med 22(3):207-220. doi: 10.1007/s00481-010-0077-9

Meijboom FLB (2007) Trust, food and health. Questions of trust at the interface between food and health. J Agric Env Ethics 20(3):231-245
Meijboom FLB (2008) Problems of trust: a question of trustworthiness. An ethical inquiry of trust and trustworthiness in the context of the agricultural and food sector. Utrecht University, Utrecht

Mill JS [1859] (1974) On liberty. Penguin Books, Suffolk

Nordström K (2009) Autonomie und Erziehung. Eine ethische Studie (Autonomy and education. An ethical study). Karl Alber, Freiburg

Sacks G, Veerman GL, Moodie M, Swinburn B (2011) 'Traffic-light' nutrition labelling and 'junk-food' tax: a modelled comparison of cost-effectiveness for obesity prevention. Int $\mathrm{J}$ Obes 35: 1001-1009

Say R, Murtagh M, Thomson R (2006) Patients' preference for involvement in medical decision making: a narrative review. Patient Educ Couns 60(2):102-114

Shiloh S (1996) Decision-making in the context of genetic risk. In: Marteau T, Richards M (eds) The troubled helix: social and psychological implications of the new human genetics. Cambridge University Press, Cambridge, pp 82-103

Smed S (2012) Financial penalties on foods: the fat tax in Denmark. Brit Nutr Found Nutr Bull 37:142-147

Stewart-Knox BJ, Bunting BP, Gilpin S et al (2009) Attitudes toward genetic testing and personalised nutrition in a representative sample of European consumers. Br J Nutr 101:982-989

Tiffin R, Arnoult M (2011) The public health impacts of a fat tax. Eur J Clin Nutr 65:427-433 